\title{
WT1 Peptide Vaccine OCV-501
}

National Cancer Institute

\section{Source}

National Cancer Institute. WT1 Peptide Vaccine OCV-501. NCI Thesaurus. Code C106257.

A peptide cancer vaccine comprised of a peptide derived from Wilms tumor gene 1 (WT 1) protein, with potential immunomodulating and antineoplastic activities. Upon subcutaneous administration, WT1 peptide vaccine OCV-501 may stimulate a CD4positive helper T-lymphocyte-mediated immune response against WT 1 expressing cells. WT 1 protein, a zinc finger DNA-binding protein, is overexpressed in leukemic cells and in some solid tumors. 